\title{
Using technique vibration diagnostics for assessing the quality of power transmission line supports repairs
}

\author{
Aleksander Cherpakov ${ }^{1,2, *}$, Inna Egorochkina ${ }^{1}$, Elena Shlyakhova ${ }^{1}$, Aleksander \\ Kharitonov ${ }^{1}$, Anatoliy Zarovny ${ }^{1}$, and Svetlana Dobrohodskaya ${ }^{1}$ \\ ${ }^{1}$ Don State Technical University, pl. Gagarina, 1, Rostov-on-Don, 344010, Russia \\ ${ }^{2}$ Southern Federal University, pr. Stachki, 200/1, k.1, Rostov-on-Don, 344090, Russia
}

\begin{abstract}
The considered method for assessing the quality of the repair work to restore the rack supports of transmission lines is based on the method of vibration diagnostics. Power transmission line supports with a symmetrical destruction of the protective layer of concrete in the ground in violation of the construction section were chosen as an object. Finite element modelling package Ansys was used in assessing the quality of repair work. The example of evaluating the quality of repair using the relative adhesion defective area design criteria in the analysis of natural vibration frequencies is given.
\end{abstract}

\section{Introduction}

Existing recommendations for repair of reinforced concrete structures contain the methodology and the recommended sequence of repairs, establish requirements for the repair materials and technical means to carry out these works. The compositions and mixtures of types of repair are selected taking into account the technical requirements for the design, economic efficiency and specificity of the region [1-3].

Results mainly repairs evaluated visually that an objective assessment of insufficient quality. One of the alternatives is to assess the state of the construction method of nondestructive testing using vibration diagnosis based on the analysis of the parameters of their own design oscillations [4-11].

This method can be implemented on the basis of specific algorithms, mathematical processing of the input information about the vibrations design and solution of inverse problems of the theory of vibrations to restore the missing information about the parameters of the core structure [12-17]. In [18-19] shows the process of modeling vibrations corpulent beam structure with defects. As the rod structures cantilever type can be considered exploited concrete pillars stand electrical transmission line.

For the identification of defects and determination of the critical state of development of generalized design criteria required. In the process of diagnostics set types, localization, defect parameters, the volume of planned repair work, etc.

\footnotetext{
* Corresponding author: alex837@yandex.ru
} 
This material is well represented in [20-22]. Analysis of the research shows that the use of the vibration method allows you to quickly and effectively assess the state of the structure. In constructing the problem of identification of defects and find effective solutions need to be clarified the most typical localization of damage. The system is considered an example of identification presents an analysis of options dangerous defect localization cantilever type beam structures on the example of the rack line supports support is the base of the zone.

The aim of the research is to develop a condition assessment methods and quality control of the repair work on the restoration of one of the elements of power transmission line (PTL) - rack supports, based on the method of vibration diagnostics.

\section{Materials and Methods}

\subsection{Object of study}

As the object of study selected rack concrete supports of type of power transmission line SV 95-3 (in Russia), which is a solid brick structure, which is in operation for more than 20 years, with a symmetrical destruction of the protective layer of concrete in the foundation and opening of cracks, in violation of the construction section (Figure 1) that It is a necessary condition for its overhaul.
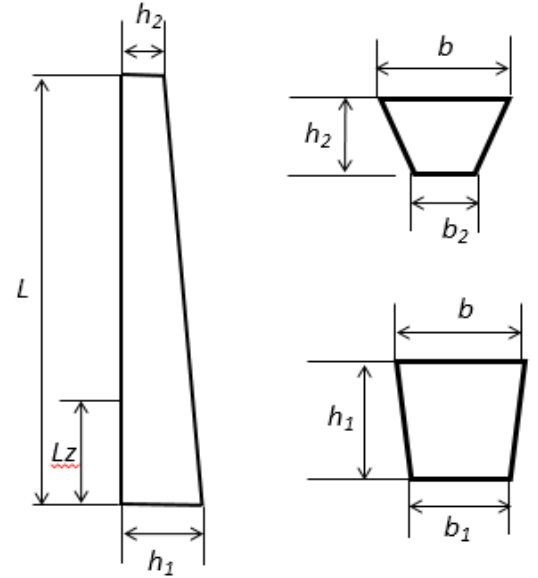

a)

$\begin{array}{ll}\begin{array}{l}\text { Mark of } \\ \text { support }\end{array} & \text { SV 95-3 } \\ M, T & 0,8 \\ L, M M & 9500 \\ L z, M M & 1850 \\ b, M M & 185 \\ b_{1}, M M & 175 \\ h_{1}, M M & 265 \\ h_{2}, M M & 165\end{array}$

b)

Fig. 1. Reinforced rack SV 95-3: a) the geometric parameters of the PTL; b) the type of defect.

Selection of repair compounds for the repair of surface defects and restore section overhead transmission line supports strut design has been based on the analysis of the normative and technical documentation [1-3]. In this paper, as the repair composition used modified fine concrete that meets regulatory requirements.

To assess the quality of repairs to restore the concrete pillar determines the amount of adhesion of repair layers to the substrate (concrete pillar) by vibration diagnostics. For the modeling area with simulated different variants of values of adhesion layers to the base repair includes the following cases:

1. coupling the layers together complete;

2. adhesion between the layers partially;

3. adhesion between the layers is virtually absent. 
In subsequent calculations options considered pronounced geometric size of the adhesion area.

\subsection{Modeling}

Modeling symmetrical failure of the bearing structure of the protective layer of concrete at the base of the oscillation in violation of the construction section (the defect) carried out in a complex finite element (FE) Ansys. As a criterion for assessing the effectiveness of rehabilitation work taken relative value of adhesion. The modeling is based dependence of the parameters of natural frequencies at different values of the adhesion area.

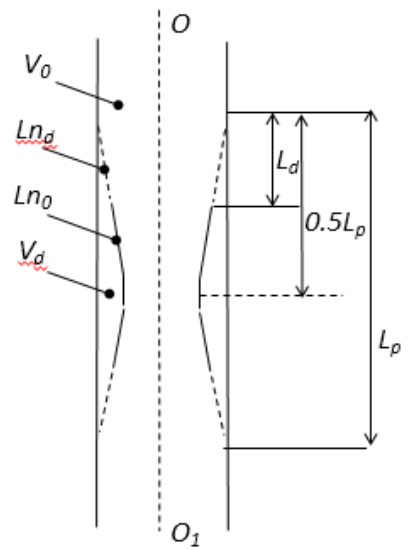

Fig. 2. Arrangement of areas in the support pillar of the defect area.

Scheme a defective design area is shown in Figure 2. The figure shows: $V_{0}$ - intact area of support; $V_{d}$ - the defect area, has undergone repair; $L_{p}$.- the length of the damage; $L n_{0}$ complete clutch repair area and base layers; $L n_{d}$ - region in violation of the clutch repair and base layers.

The relative value of adhesion $\bar{t}$, can be estimated as the ratio of the area in violation of contact between the repaired and the base layer to the total length of the damaged area:

$$
\bar{t}=\frac{L_{p}-2 L_{d}}{L_{p}}
$$

FE model without damaging the bearings can be represented in the form of threedimensional beam corpulent $3 \mathrm{D}$ structure having rigid fastening at the base nodes. Finite element model of reinforced concrete pillars with a defect in the base shown in Figure 3. An area with $L_{f d}$ damage located on a distance from the lower end of the support.

FE model without damaging the bearings can be represented in the form of threedimensional beam corpulent $3 \mathrm{D}$ structure having rigid fastening at the base nodes. Finite element model of reinforced concrete pillars with a defect in the base shown in Figure 3. An area with $L_{f d}$ damage located on a distance from the lower end of the support. 

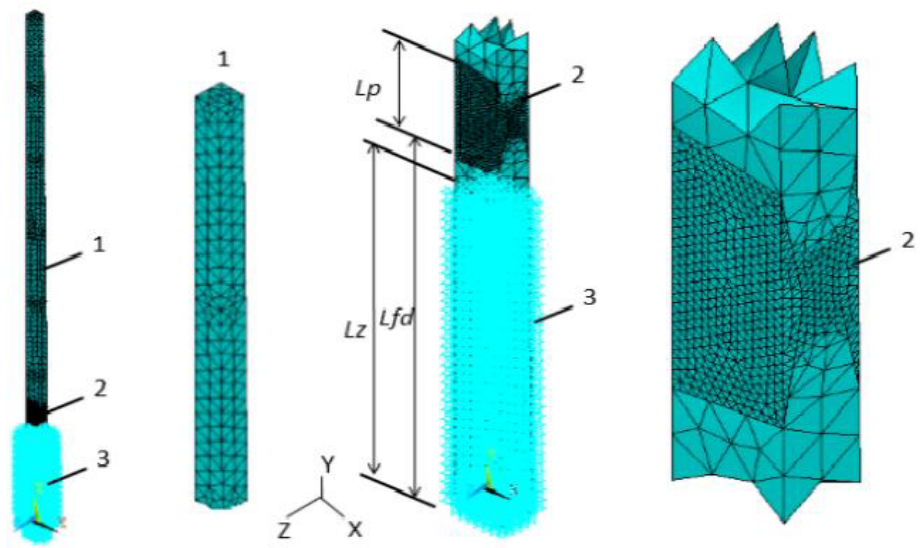

Fig. 3. The finite element model of reinforced concrete pillar with a support base in the field of defect: 1 fragment of the support without damage; 2 - damaged area, 3 - area of the base of support with rigid fixation of the mesh nodes FE on the surface.

The area is the site of injury thickening finite element mesh as compared to the undamaged area. For the lower part of the support to move the nodes of the finite element mesh model on surfaces made rigidly fixed, thereby fixing wondered conditional support. For the calculation model parameters ground mass stiffness is not taken into account at the base of support.

\section{Results}

The calculation for the area with simulated damage taken following characteristics repair mix: the modulus of elasticity of $3.45 * 10^{9} \mathrm{~Pa}$, the strength of 28 day old $35.8 \mathrm{MPa}$, density of $2320 \mathrm{~kg} / \mathrm{m}^{3}$, the adhesion with the concrete base of $1.6 \mathrm{MPa}$.

Simulation of a defect-free region was considered as a full contact $V_{0}$ support volumes and the repaired area $V_{d}$. The results of calculation of the natural frequencies of the support model fluctuations without damage are shown in Table 1 . The natural frequencies are used as a base for further calculation of the value of adhesion. In the next step the natural frequencies are calculated with different structural oscillations adhesion value $\bar{t}$, and set the relative values $\Delta \omega$ i own frequency according to the Equation 2.

$$
\Delta \omega_{i}=\frac{\omega_{d i}-\omega_{0 i}}{\omega_{d i}} 100 \%
$$

Table 1. The natural frequencies of the support model variations and their relative values with the value of adhesion $\bar{t}=0.05$.

\begin{tabular}{|c|c|c|}
\hline $\begin{array}{c}\text { Mode } \\
\text { oscillation }\end{array}$ & $\begin{array}{c}\text { The absolute values of the natural frequencies of } \\
\text { oscillation, } \mathbf{H z}\end{array}$ & $\begin{array}{c}\text { Relative Frequency } \\
\Delta \omega_{d i}(\bar{t}=0.05), \%\end{array}$ \\
\hline 1 & $\omega_{0 i}(\bar{t}=1) / \omega_{d i}(\bar{t}=0.05)$ & -17.70 \\
\hline 2 & $0.6363 / 0.5237$ & -4.11 \\
\hline 3 & $0.8176 / 0.784$ & -8.94 \\
\hline 4 & $3.6713 / 3.3431$ & -2.82 \\
\hline
\end{tabular}


Built a graphical display of dependencies $\Delta \omega_{d i}$ relative values of natural frequencies of the value of adhesion $\bar{t}$.

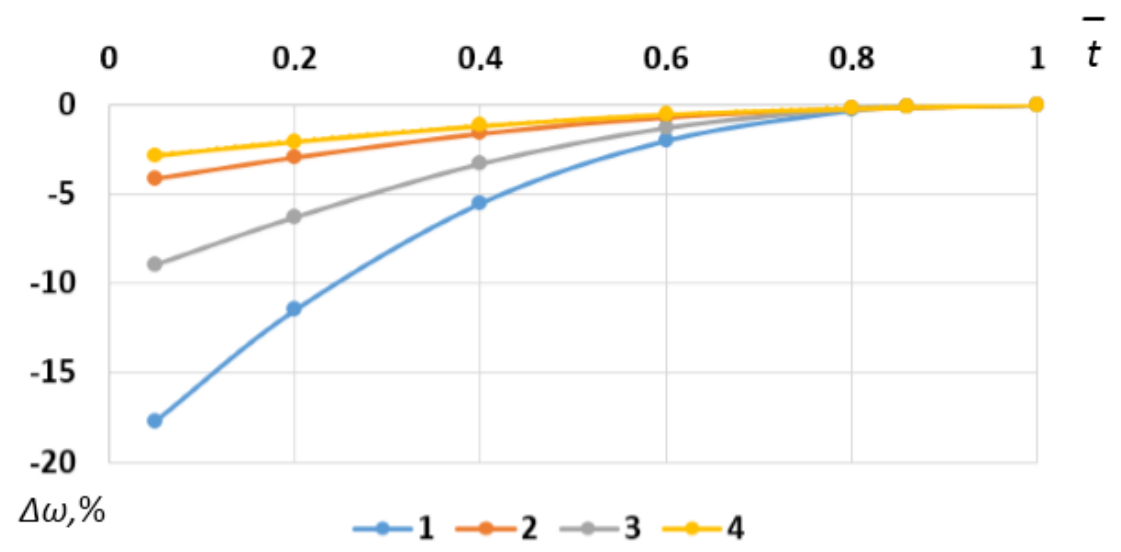

Fig. 4. The dependence of the damage caused by the relative change in the first four natural frequencies of oscillation $\Delta \omega_{d}$ design stand defective bearings.

For selected events with different sensitivity to changes in the natural frequencies of the magnitude of adhesion were obtained correlation equations depending on the estimated relative frequency of their own 1-4 modal $\bar{t}_{M i}\left(\omega_{d i}\right)$ to the value of adhesion with certainty approximation $\mathrm{R}>0,95$. On the basis of the dependence of each oscillation mode in the presence of the relative change in the parameter value of the natural frequency of the adhesion of the repair area can be determined. According to the results obtained for the average value of each mode of damage can be calculated as:

$$
\bar{t}_{\mathrm{cp}}=\frac{\sum_{1}^{N} \bar{t}_{M i}\left(\Delta \omega_{i}\right)}{N_{M}}
$$

\section{Discussion}

As an example, the equation constructed dependence of adhesion on the relative change in the natural frequencies of the previously defined dimensions of injury.

Example assessment of the repair area of the model structure of adhesion. To perform calculations with the model of the previously described dimensions. Adopted by the value of the repair composition of the adhesion to the substrate, which is equal to $\bar{t}=0.2$. Produced modeling spectral analysis in Ansys complex. We obtained the following natural frequencies of the model: $\omega_{d 1}=0.563 \mathrm{~Hz}, \omega_{d 2}=0.794 \mathrm{~Hz}, \omega_{d 3}=3.44 \mathrm{~Hz}, \omega_{d 4}=4.255$ Hz. By using data from a table 1 of natural frequencies model with full adhesion of the repaired area with the previously defined parameters we calculate relative changes in frequency according to the formula (2): $\Delta \omega_{d 1}=-11.494 \%, \Delta \omega_{d 2}=-2.935 \%, \Delta \omega_{d 3}=-$ $6.295 \%, \Delta \omega_{d 4}=-2.059 \%$. Based on these dependencies determines the amount of adhesion. Results are presented in Table 2. 
Table 2. The results of calculation of the adhesion values.

\begin{tabular}{|c|c|c|c|}
\hline $\begin{array}{c}\text { Mode } \\
\text { oscillation }\end{array}$ & $\begin{array}{c}\text { Natural frequencies } \\
\omega_{d i}(\bar{t}=\mathbf{0 . 2}),(\mathbf{H z}) \\
\text { oscillation }\end{array}$ & $\begin{array}{c}\text { The relative } \\
\text { frequency of its } \\
\text { own } \Delta \omega_{d i}, \%\end{array}$ & $\begin{array}{c}\text { The } \\
\text { value of } \\
\text { adhesion }\end{array}$ \\
\hline $\bar{t}_{M i}\left(\omega_{d i}\right)$
\end{tabular}

For the obtained numerical simulation results define error in determining the value of adhesion:

$$
\Delta \bar{t}=\left|\frac{\bar{t}_{c p}-\bar{t}_{0}}{\bar{t}_{0}}\right| 100 \%=\left|\frac{0.206-0.2}{0.2}\right| 100 \%=3 \%
$$

In this example, the calculation of the value of adhesion is $\bar{t}_{c p}=0.206$. Deviation from the desired value of adhesion is $\Delta \bar{t}=3 \%$. These values are estimates.

\section{Conclusions}

1. A method for assessing the quality of the repair work to restore the rack supports of overhead power lines on the basis of the method of vibration diagnostics.

2. The criterion of assessing the quality of repair work to restore the design section relative value of adhesion.

3. The example of plotting the relative frequency of its own full-bodied design of the oscillation of the relative value of adhesion.

4. Calculation of assessing the relative value of adhesion to concrete repair mortar model design stand.

5. Evaluation of the critical state of the core structure requires further research on the example of a corpulent simulation with finite element approach.

\section{Acknowledgements}

The research was partially supported by the proposal of the Russian Department of Education and Science No. BCh0110-11/2017-20 and the Russian Foundation for Basic Research (grants Nos. 16-08-00740-a, 14-08-00546-a, 14-38-50915, 17-08-00621-a, 17-0801373-a)

\section{References}

1. E.A. Shlyakhova, A.I. Kholostova, ESJ Engineering Journal of Don, 4 (2013)

2. I.O. Egorochkina, Vestnik Yuzhno-Ural'skogo gosudarstvennogo universiteta 3, 49-53 (2014) 
3. E.A. Shlyakhova, A.M. Piterskiy, pat. 2548263 S1, RGSU, 11 (2015)

4. O.A. Burtseva, S.A. Chipco, O.K. Kaznacheeva, A.V. Cherpakov, European Journal of Natural History, 4, 39-44 (2012)

5. I.O. Egorochkina, Ya.I. Kostyrya, ESJ Engineering Journal of Don, 4 (2015)

6. A.V. Cherpakov, V.A. Akop'yan, A.N. Solov'ev, EJ Technical Acoustics, 13 (2013)

7. I.O. Egorochkina, E.A. Shljahova, A.V. Cherpakov, A.N Solov'ev, ESJ Engineering Journal of Don, 4 (2015)

8. I.O. Egorochkina, E.A. Shlyahova, A.V. Cherakov, L.A. Manvelyan, D.Yu. Kucherenko, ESJ Engineering Journal of Don, 44 (2016)

9. A. Del Grosso, F. Lanato, Proc. Eur. Conf. on Structural Control, 1, 320-327 (2008)

10. M. Dilena, On damage identification in vibrating beams from changes in node positions (Springer, New York, 2003)

11. A.G. Khakimov, E.I. Satyev, ESJ Oil and Gas Business, 6, 120-153 (2014)

12. V.A. Akopyan, A.N. Solov'ev, A.V. Cherpakov, S.N. Shevtsov, Russian Journal of Nondestructive Testing, 49(10), 579-583 (2013)

13. A.A. Krasnoshchekov, B.V. Sobol, A.N. Solov'ev, A.V. Cherpakov, Russian Journal of Nondestructive Testing, 47(6), 412-419 (2011)

14. O.V. Bocharova, A.V. Sedov, I.E. Andzhikovich, V.V. Kalinchuk, Russian Journal of Nondestructive Testing, 52(7), 377-382 (2016)

15. A.N. Soloviev, A.V. Cherpakov, I.A. Parinov, Analytical Modeling Identifying the Location of Multiple Cracks in the Rod Construction (Nova Science Publishers, New York, 2016)

16. A.N. Soloviev, A.V. Cherpakov, E.V. Rozkov, I.A. Parinov, Vibrodiagnostics of Truss Model with Damages. Experiment (Nova Science Publishers, New York, 2016)

17. V. Akopyan, A. Soloviev, A. Cherpakov, Parameter Estimation of Pre-Destruction State of the Steel Frame Construction Using Vibrodiagnostic Methods (Nova Science Publishers, New York, 2011)

18. A.V. Cherpakov, R.A. Kayumov, E.E. Kosenko, I.Z. Mukhamedova, Bulletin of Kazan Technological University, 17(10), 182-184 (2014)

19. V.A. Akopyan, A.N. Soloviev, A.N. Kabelkov, A.V. Cherpakov, University news, 1, 55-58 (2009)

20. V.A. Akopyan, A.V. Cherpakov, E.V. Rozhkov, A.N. Soloviev, Control. Diagnostics, 7, 50-56 (2012)

21. V.A. Akopyan, E.V. Rozhkov, A.N. Solovyov, S.N. Shevtsov, A.V. Cherpakov, Southern Federal University Publishing, 1-74 (2015)

22. A.V. Cherpakov, A.N. Soloviev, V.V. Gricenko, O.U. Goncharov, Defence Science Journal, 1, 44-50 (2016) 